\title{
Design and Performance of Capping Layers for EUV Multilayer Mirrors
}

S. Bajt, H. N. Chapman, N. Nuygen, J. Alameda, J. C. Robinson, M. Malinowski, E. Gullikson, A. Aquila, C. Tarrio, S. Grantham

This article was submitted to $28^{\text {th }}$ Annual International Symposium on Microlithography, Santa Clara, Ca, February 23-27, 2003

Lawrence

Livermore

National

Laboratory

\section{March 10, 2003}

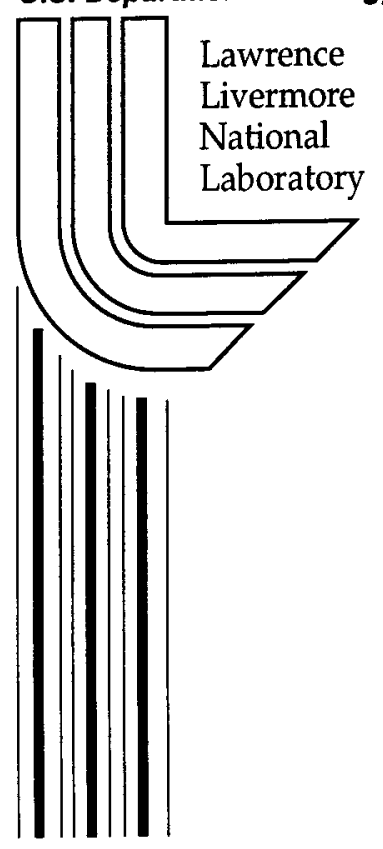




\section{DISCLAIMER}

This document was prepared as an account of work sponsored by an agency of the United States Government. Neither the United States Government nor the University of California nor any of their employees, makes any warranty, express or implied, or assumes any legal liability or responsibility for the accuracy, completeness, or usefulness of any information, apparatus, product, or process disclosed, or represents that its use would not infringe privately owned rights. Reference herein to any specific commercial product, process, or service by trade name, trademark, manufacturer, or otherwise, does not necessarily constitute or imply its endorsement, recommendation, or favoring by the United States Government or the University of California. The views and opinions of authors expressed herein do not necessarily state or reflect those of the United States Government or the University of California, and shall not be used for advertising or product endorsement purposes.

This is a preprint of a paper intended for publication in a journal or proceedings. Since changes may be made before publication, this preprint is made available with the understanding that it will not be cited or reproduced without the permission of the author.

This work was performed under the auspices of the United States Department of Energy by the University of California, Lawrence Livermore National Laboratory under contract No. W-7405-Eng-48.

This report has been reproduced directly from the best available copy.

Available electronically at http://www.doc.gov/bridge

Available for a processing fee to U.S. Department of Energy

And its contractors in paper from

U.S. Department of Energy

Office of Scientific and Technical Information

P.O. Box 62

Oak Ridge, TN 37831-0062

Telephone: (865) 576-8401

Facsimile: (865) 576-5728

E-mail: reports@adonis.osti.gov

Available for the sale to the public from

U.S. Department of Commerce

National Technical Information Service

5285 Port Royal Road

Springfield, VA 22161

Telephone: (800) 553-6847

Facsimile: (703) 605-6900

E-mail: orders@ntis.fedworld.gov

Online ordering: http://www.ntis.gov/ordering.htm

OR

Lawrence Livermore National Laboratory

Technical Information Department's Digital Library

http://www.llnl.gov/tid/Library.html 


\title{
Design and performance of capping layers for EUV multilayer mirrors
}

\author{
Sasa Bajt ${ }^{*}$, Henry N. Chapman ${ }^{a}$, Nhan Nuygen ${ }^{a}$, Jennifer Alameda ${ }^{a}$, Jeffrey C. Robinson ${ }^{a}$, \\ Michael Malinowski ${ }^{\mathrm{b}}$, Eric Gullikson ${ }^{\mathrm{c}}$, Andy Aquila ${ }^{\mathrm{c}}$, Charles Tarrio ${ }^{\mathrm{d}}$, Steven Grantham ${ }^{\mathrm{d}}$ \\ ${ }^{a}$ Lawrence Livermore National Laboratory, 7000 East Avenue, Livermore, CA 94550, USA; \\ ${ }^{\mathrm{b}}$ Sandia National Laboratories, 7011 East Avenue, Livermore, CA 94550, USA; \\ 'Lawrence Berkeley National Laboratory, CXRO, Berkeley, CA 94720, USA; \\ ${ }^{d}$ National Institute of Standards and Technology, Gaithersburgh, MD 20899, USA
}

\begin{abstract}
The reflectance stability of multilayer coatings for extreme ultraviolet lithography (EUVL) in a commercial tool environment is of uttermost importance to ensure continuous exposures with minimum maintenance cost. We have made substantial progress in designing the protective capping layer coatings, understanding their performance and estimating their lifetimes based on accelerated electron beam and EUV exposure studies. Our current capping layer coatings have about 40 times longer lifetimes than Si-capped multilayer optics. Nevertheless, the lifetime of current Ru-capped multilayers is too short to satisfy commercial tool requirements and further improvements are essential.
\end{abstract}

Keywords: Extreme ultraviolet (EUV) lithography, multilayers, optics, capping layer, ruthenium, oxidation resistance, reflectivity

\section{INTRODUCTION}

The next generation extreme ultraviolet lithography (EUVL) is based on Mo-Si coated reflective optics optimized for $13.5 \mathrm{~nm}$ wavelength. Recent high-quality Mo-Si multilayers have been made using DC magnetron sputtering ${ }^{1} \mathrm{RF}$ magnetron sputtering ${ }^{2}$, ion beam sputtering ${ }^{3}$, electron beam evaporation with ion beam polishing ${ }^{4}$, pulsed laser deposition $^{5}$ and rotary magnetron sputtering. However, the highest reported reflectivities are achieved with DC magnetron sputtering ${ }^{7-8}$ using interface-engineered multilayers in which the Mo and the Si layers are separated with thin layers of low $\mathrm{Z}$ materials such as $\mathrm{B}_{4} \mathrm{C}$ or $\mathrm{C}$. The reflectivity of multilayer coatings is of great importance because the optical throughput of the EUVL tools is proportional to:

$$
\int R^{n}(\lambda) d \lambda
$$

where $\mathrm{R}$ is the reflectance of the multilayer and $\mathrm{n}$ is the number of reflective mirrors in the EUVL tool. For commercial EUVL optical trains $n$ is typically 9 or higher and even a small change in reflectivity of about $1 \%$ will lead to a noticeable change in the throughput of such a system. It is believed that an EUVL tool should be able to expose 100 to $120,300 \mathrm{~mm}$ wafers $/ \mathrm{hr}$ to be commercially viable. A breakthrough in source development is needed but improvements in multilayer reflectivity will make this goal more feasible. However, in addition to the essential high reflectivity the multilayers must maintain their performance over a reasonably long operating lifetime. The lifetime of multilayers is currently one of the highest risks for EUVL commercial viability. Mo-Si multilayers have traditionally been terminated with a Si layer, which forms a thin and stable oxide in the air. For an ideal multilayer it would be better to terminate the multilayer with molybdenum absorber layer. However, it was shown early on that molybdenum is not stable in the air? Early studies of the silicon-capped multilayer lifetimes ${ }^{10}$ were done in a good vacuum of $<5 \times 10^{-8}$ mbar. Based on the results from EUV exposures under these conditions it was extrapolated that a yearly dose will not significantly alter the

*bajt(allnl.gov; phone: 1925424 3768; fax 19254231488 
performance of $\mathrm{x}$-ray optics if the optics is maintained in high vacuum conditions. We have found, however, that for multilayers in the environments of commercial tools, these estimates are overly optimistic.

The optical systems of EUV lithographic tools will operate in unbaked vacuum systems ${ }^{11}$. Therefore, it is crucial that lifetime tests of multilayers are performed in relevant environments, where the main contaminants are water vapor and hydrocarbons ${ }^{12-14}$. Ideally the tests should be performed by exposing the multilayers with the EUV source planned to be used in the commercial tools. Because the sources are still being developed, and there is a limited amount of time available for these experiments on high brightness synchrotron beamlines, the experiments are often performed with electron beams ${ }^{1,}{ }^{15}$. It has been demonstrated that molecular contamination is caused by EUV induced secondary electrons. Electron-beam exposure experiments are tailored to give a similar energy distribution of secondary electrons and depth penetration as the EUV exposures to attempt to cause the same amount of damage, however, there is still much unknown about the relationship between the EUV- and electron beam-induced damage. A recent study focused on oxidation caused by EUV-and electron-beam exposure of Si-capped multilayers ${ }^{16}$. The oxidation mechanism is likely very different for different material and this paper presents the results of EUV-and electron beam-induced oxidation on $\mathrm{Si}$ - and $\mathrm{Ru}$-capped multilayers under one particular environmental condition.

The main contamination for projection optics is carbon deposition and oxidation. Condenser optics are exposed to quite different environment to the projection optics and require different solutions for lifetime improvements ${ }^{17}$. For example, the first condenser optic, which collects light from the plasma source usually has a direct line of sight to the plasma and is susceptible to sputtering, implantation, carbon deposition, oxidation and debris contamination. In general, the condenser optics are also exposed to a broader spectrum and higher heat load than the projection optics and require active cooling in order to minimize thermal induced multilayer effects such as wavelength shift and reflectance loss. Fortunately, the specifications for condenser optics are less stringent and possible solutions include economic, replaceable substrates and removable coatings ${ }^{18}$.

The topic of this paper is the lifetime of projection optics. The projection optics have very stringent requirements for fabrication, multilayer deposition, and alignment and must have lifetimes of at least 5 years. We define the lifetime as the time in which each individual projection optic is allowed to lose up to $1.6 \%$ (absolute) in reflectance. The lifetime of projection optics is limited by two effects: carbon deposition and oxidation. It has been demonstrated that carbon can be removed, for example, by using RF oxygen, RF hydrogen ${ }^{19}$, atomic hydrogen ${ }^{20}$ and ozone ${ }^{12,}{ }^{14}$ with only a minor degradation of mutilayer reflectivity. Avoiding carbon deposition is an even better solution. This idea was proposed by Klebanoff et al. ${ }^{13}$ who showed that carbon deposition is substantially reduced in an environment where there is a mixture of water vapor and ethanol. Oxidation is more problematic because once an oxide is formed it can not be removed. Oxides also strongly absorb EUV light and for example, a small increase of $1.5 \mathrm{~nm}$ in oxide layer is sufficient to decrease reflectance by $1.6 \%$ (absolute), the lifetime budget for projection optics. Oxidation resistant capping layers are essential to increase EUV multilayer lifetimes.

Different capping layer materials have been proposed to be used on Mo-Si multilayers based on their optical constants ${ }^{21}$. However, in addition to optical properties, capping materials need to meet other criteria to be good candidates for oxidation resistant materials. The material has to form a continuous layer for thickness of few $\mathrm{nm}$, it has to form a sharp, smooth interface with the material underneath and has to be oxidation resistant in water vapor environment. Unfortunately, the data about EUV induced oxidation in the presence of water vapor is very scarce. Most of the data have been collected only recently on Si-capped Mo-Si multilayers ${ }^{14}$, ${ }^{16}$. Initial results on promising oxidation resistant capping layers include $\mathrm{Ru}^{7}$ and C-layers ${ }^{22}$.

\section{EXPERIMENTAL METHODS}

\subsection{Deposition System and Sputtering Rate Calibration}

Multilayers were deposited using a DC-magnetron sputtering system described previously by Bajt et al. ${ }^{7}$. In this system in which the substrates are rotated on a platter above a circular arrangement of targets, two of the sputtering guns, placed 180 degrees apart, are rectangular $(12.7 \times 25.4 \mathrm{~cm})$, and two are circular $(10 \mathrm{~cm})$. This geometry places each sputtering 
gun into its own quadrant. The two large sputtering guns are used to sputter Mo and $\mathrm{Si}$, while the small sputtering guns are used to sputter $\mathrm{B}_{4} \mathrm{C}$ (for interfacial barriers) and $\mathrm{Ru}$, respectively. The sputtering guns, which are mounted on the bottom of the deposition chamber, are facing up, while the substrates, mounted on the rotating platter are facing down. Using this setup, up to two substrates with different multilayer design can be coated per deposition run. The substrates, which spin during the deposition, are usually super-polished $\mathrm{Si}(100)$ wafers. Most of the coatings for this study were done on $100 \mathrm{~mm}$ diameter substrates. The platter with affixed substrate spinners rotates over the sputtering targets during the deposition and the platter rotational velocity controls the individual layer thickness. The deposition runs for this study were done at $1 \mathrm{mTorr}$ of ultrahigh-purity Ar gas with a chamber base pressure of $2 \times 10^{-7}$ Torr or better. Applied powers of $360 \mathrm{~W}$ on $\mathrm{Si}, 170 \mathrm{~W}$ on $\mathrm{Mo}, 100 \mathrm{~W}$ on $\mathrm{B}_{4} \mathrm{C}$ and $50 \mathrm{~W}$ on $\mathrm{Ru}$ targets were used, respectively.

The sputtering rates of the Mo and Si targets were calibrated by depositing multilayes in which the velocity of the platter was varied over the sources at constant power, and subsequently determining the $\mathrm{Mo} / \mathrm{Si}$ multilayer periods by fitting the Bragg peaks in the small angle $\mathrm{x}$-ray diffraction spectra in the variable-period multilayers. The sputtering rates of $\mathrm{B}_{4} \mathrm{C}$ and $\mathrm{Ru}$ were determined from single films coated at constant power. Small angle $\mathrm{X}$-ray diffraction measurements were performed with a Rigaku DMAX-IIB diffractometer with a $\mathrm{Cu} \mathrm{K}_{-}$rotating anode source $(\lambda=0.154 \mathrm{~nm})$.

\subsection{EUV Reflectometry}

The synchrotron-based reflectometer at beamline 6.3.2. at the Advanced Light Source (ALS, Lawrence Berkeley National Laboratory) is ideally suited for characterization of multilayer coated optics and was used to measure the reflectance of our multilayers. This reflectometer has high stability, high spectral purity, and small beam diameter ${ }^{23}$. This reflectometer can routinely achieve a wavelength precision of $0.002 \mathrm{~nm}$ and reflectance repeatability of $\pm 0.2 \%$. Beamline software allows collection of individual reflectance spectra, line scanning or 2D mapping.

\subsection{Atomic Force Microscopy (AFM)}

The surface roughness of the multilayers was characterized using a Digital Instruments Dimension 3000 Atomic force microscope (AFM), operating in tapping mode. The AFM is fitted with a Nanoscope IIIA Controller, a phase extender box and standard Si tip. The surface roughness was measured on each sample over an area of $2 \times 2$.

\subsection{Auger Electron Spectroscopy (AES)}

Auger electron spectroscopy was used to identify the elemental composition of the multilayers. An ion beam sputter source was used to remove less than one monolayer of material from the surface at a time during continued monitoring of Auger electron spectra to determine the composition and chemistry of the exposed surface. A PHI660 scanning Auger microprobe was operated at $5 \mathrm{keV}$ and $75 \mathrm{nA}$, and the beam was rastered over a $50 \times 50 \_\mathrm{m}$ area at $30^{\circ}$ from normal incidence. A PHI Duoplasmatron ion source was operated at $2 \mathrm{keV}$ and $8 \mathrm{nA}$ current at a $45^{\circ}$ angle. Sputtering rates of $\mathrm{Mo}$ and $\mathrm{Si}$ within the multilayer were calibrated using the known multilayer period, which was determined by small angle $\mathrm{x}$-ray diffraction or EUV reflectometery. No attempt was made to adjust sputtering rates for the $\mathrm{Ru}$ and $\mathrm{B}_{4} \mathrm{C}$ capping layers.

\subsection{X-ray Photoelectron Spectroscopy (XPS)}

Additional compositional information of the multilayers was obtained by XPS. The XPS data were collected using a Quantum 2000 scanning XRS system with a focused monochromatic Al K x-ray $(1486.7 \mathrm{eV})$ source of excitation and a spherical section analyzer. The instrument has a 16-element multichannel detection system. A $200 \_\mathrm{m}$ diameter $\mathrm{x}$-ray beam was used for analysis. The $\mathrm{x}$-ray beam was incident normal to the sample and the electron detector was at $45^{\circ}$ away from normal. The pass energy was $23.5 \mathrm{eV}$ giving overall energy resolution of $0.3 \mathrm{eV}$. The collected data were referenced to an energy scale with binding energies for $\mathrm{Cu} 2 \mathrm{p}_{3 / 2}$ at $932.72 \pm 0.05 \mathrm{eV}$ and $\mathrm{Au} 4 \mathrm{f}_{7 / 2}$ at $84.01 \pm 0.05 \mathrm{eV}$. Binding energies were also referenced to the $\mathrm{Cls}$ photoelectron line arising from adventitious carbon at $284.6 \mathrm{eV}$. Low energy electrons and argon ions were used for specimen neutralization.

\subsection{Electron Beam Exposures}


Electron beam exposures were performed in a carbon system at Sandia National Laboratories in Livermore (see Figure 1). The system consists of two small, differentially pumped chambers. This is necessary in order to simultaneously have the electron beam gun in a good vacuum $\left(10^{-9} \mathrm{Torr}\right)$ for stable operation and the sample in an oxidizing environment $\left(10^{-}\right.$ ${ }^{7}-10^{-6}$ Torr $\mathrm{H}_{2} \mathrm{O}$ partial pressure). Electrons with $1 \mathrm{keV}$ energy and $500 \_\mathrm{A} / \mathrm{cm}^{2}$ current density were used in this study. The beam area on the sample was estimated to be about $2 \mathrm{~mm}^{2}$. The sample chamber can accommodate one small sample $(-2.5 \times 1.25 \mathrm{~cm})$ and a phosphorous screen. The phosphorous screen was used to check the shape, size and position of the electron beam on the sample. A variable leak valve with an attached high purity $\mathrm{H}_{2} \mathrm{O}$ cylinder was used to adjust $\mathrm{H}_{2} \mathrm{O}$ partial pressure in the sample chamber and a Residual Gas Analyzer (RGA) monitored the quantity of water and other impurities in the chamber. The pressure and the secondary electron yield were recorded as a function of time during the exposures. The secondary electron yield (SEY) emission is defined as a ratio of the secondary electron current to the primary electron current. The primary electron current is measured by applying a $100 \mathrm{~V}$ bias on the sample while the secondary electron beam current is derived from the difference between the currents of the sample with an without bias applied. The beam current was stable within $\pm 20 \%$ for daylong exposures.

\subsection{Extreme Ultraviolet (EUV) Exposures}

Two samples in this study were exposed to EUV radiation in an oxidizing environment. The experiments were performed at the National Institute of Standards using a multilayer exposure beamline at SURF. A $75 \mathrm{~mm}$ diameter, 1.5 $\mathrm{m}$ radius multilayer coated spherical mirror positioned approximately $4 \mathrm{~m}$ from the tangent point of the electron beam in the ring reflects. with a deviation of $20^{\circ}$. A 0.2 m thick, mesh-backed Be foil provides both filtering of long wavelength radiation and vacuum isolation between the exposure chamber and the mirror chamber, which must be kept at a background pressure of $<20 \times 10^{-8}$ Torr (Figure 2). The light is incident on the sample at an angle of $10^{\circ}$ from normal. Incident and reflected radiation intensity are measured using a $\mathrm{Zr} / \mathrm{C}$ coated photodiode. The photoemission from the sample surface was monitored. For these measurements, a stainless steel aperture biased at $100 \mathrm{~V}$, offset $5 \mathrm{~mm}$ from the sample surface, was used. The exposures were performed using $\sim 800 \mathrm{~mW} / \mathrm{cm} 2$ current density in $2 \times 10^{-6}$ Torr of $\mathrm{H}_{2} \mathrm{O}$ vapor pressure. Accumulated 60-hours exposures were done within one week using five 12 hour shifts separated with five 12 hours of shutdown.

\section{RESULTS AND DISCUSSION}

In an earlier paper ${ }^{7}$ we reported about promising initial results of ruthenium as an oxidation resistant capping layer. In that study ruthenium was deposited either on the top of a Si layer, on the top of a Mo layer or on the top of a $\mathrm{B}_{4} \mathrm{C}$ layer. We found that $\mathrm{Ru}$ deposited directly on the top of a Si layer inter-diffused with $\mathrm{Si}$ and formed ruthenium silicide. When exposed to the electron beam in the presence of water vapor this particular capping layer did not perform well. The main disadvantage of $\mathrm{Ru}$ deposited on a Mo layer was that this results in a low reflectivity of $62 \%$. Both $\mathrm{Ru}$ and Mo are absorbers and form too thick an absorber layer for the constructive interference with the multilayer underneath. Higher reflectivity $(\sim 66 \%)$ Ru-capped multilayers were achieved with a $0.6-0.8 \mathrm{~nm}$ thick Ru layer deposited on the top of a 1.3 $\mathrm{nm}$ thick Mo layer. However, the multilayers with such thin Ru layers have not been studied for their lifetime stability.

The study described in this paper was focused on the design and performance of capping layers for EUV multilayers. Capping layers were deposited directly on the top of standard Mo/Si multilayers (starting with $\mathrm{Si}$ at the substrate and ending with Mo) with 40 bilayers unless otherwise specified. The capping layer in this study consists of three sub-layers: $\mathrm{Ru}-\mathrm{on}-\mathrm{B}_{4} \mathrm{C}-\mathrm{on}-\mathrm{Si}$, as shown in Figure 3. The main purpose of the $\mathrm{B}_{4} \mathrm{C}$ layer is to prevent interdiffusion of $\mathrm{Si}$ and $\mathrm{Ru}$ and to create a sharp $\mathrm{Ru}-\mathrm{on}-\mathrm{B}_{4} \mathrm{C}$ interface. The typical initial reflectance of $\mathrm{Ru}$-capped multilayers was $65.5 \pm 0.5 \%$ at 13.3 $\mathrm{nm}$ at $5^{\circ}$ off normal incidence, with a $5.5 \mathrm{~nm}$ peak width (Figure 4). Aging of the multilayer in air (i.e. with no EUV exposure) showed no measurable reflectance loss after six months. Each sample was characterized before and after the exposures for reflectance as a function of wavelength, for surface roughness, for surface chemistry and bonding and for chemical depth profiles using the techniques described in section 2. In addition, secondary electron yield (SEY) emission was collected during the exposures.

\subsection{Electron beam exposures}


$\mathrm{Ru}$ and Si-capped multilayers were exposed to the electron beam in the presence of water vapor, as described in Section 2.6. We will first describe the results of a Ru-capped multilayer that was exposed to the electron beam for 360 hours. The water vapor pressure, which was kept constant, was $2 \times 10^{-6}$ Torr. The partial pressure of other contaminants was $<10^{-8}$ Torr. Results from this long exposure on the Ru-capped multilayer are presented in Figure 5. Figure 5, in which the SEY is plotted as a function of exposure time, shows a dramatic change in SEY emission occurring between 50 and 100 hours of exposure. Furthermore, the reflectivity drop as a function of exposure time is strongly correlated with the changes in SEY emission (Figure 6). The reflectance loss in the first 50-60 hours $(\sim 2 \%$, absolute) is of most interest because this is greater than the maximum allowable reflectivity loss for commercial tool mirrors. However, to better understand the oxidation mechanisms we continued the exposures well beyond 60 hours. As shown in Figure 5, the initial $2 \%$ reflectivity drop within the first 60 hours of exposure, is followed with a huge reflectivity drop of $17 \%$ over the next 50 hours of exposure and another $2 \%$ reflectivity drop for the next 250 hours of exposure. Hence, for a fixed current density and water vapor pressure, the reflectivity loss rate is not linear with time and furthermore seems to be very material dependent. High frequency surface roughness was characterized with AFM as described in Section 2.3. The typical surface roughness of Ru-capped multilayers is $0.18-0.19 \mathrm{~nm} \mathrm{rms}$ on as-deposited samples and in the areas that have not been exposed to the electron beam. However, in the areas that were exposed to the electron beam in the presence of water vapor we measured substantial increase in surface roughness, as shown in Figure 6. For example, surface roughness in an area exposed for 60 hours increased to $1.19 \mathrm{~nm} \mathrm{rms}$ and for 100 hours exposure it increased to $2.87 \mathrm{~nm} \mathrm{rms}$. However, for an area exposed for a 200 hours the surface roughness became smoother ( $1.65 \mathrm{~nm} \mathrm{~ms})$ again. Interestingly, the sample exposed to the electron beam with only $10^{-8}$ Torr water vapor pressure in the system shows no measurable reflectance drop after 170 hours of exposure and no change in surface roughness. This clearly demonstrates the importance of keeping the water vapor level as low as possible in the system in order to increase the $\mathrm{x}$ ray optics lifetime.

Using the XPS technique, detailed in Section 2. 5., we compared the surface chemistry of unexposed Ru-capped sample and $\mathrm{Ru}$-capped sample that has been exposed to the electron beam and water vapor for $\sim 100$ hours. The results are shown in Figure 7. While the unexposed area shows a slightly oxidized Ru capping layer with traces of $\mathrm{C}$ and $\mathrm{N}$, we could easily detect $\mathrm{Mo}, \mathrm{Si}$ and higher concentrations of $\mathrm{C}$ and $\mathrm{O}$ in the exposed area. High-resolution core-level spectra of $\mathrm{O} 1 \mathrm{~s}, \mathrm{~B} 1 \mathrm{~s}, \mathrm{Ru} 3 \mathrm{~d}+\mathrm{Cls}$, Mo $3 \mathrm{~d}$ and $\mathrm{Si} 2 \mathrm{p}$ for different exposure times indicate that $-\mathrm{OH}, \mathrm{O}$ and/or $\mathrm{H}$ reach the $\mathrm{B}_{4} \mathrm{C}$ layer within the first 60 hours of exposure, and change the chemical state (bonding) of the $\mathrm{B}_{4} \mathrm{C}$. Boron is undetectable in spots which were exposed to 100 hours or longer. We confirmed this with Auger depth profiles that show trace amounts of $B$ and $C$ on the surface but no defined layer of $B_{4} C$ underneath the Ru layer. XPS data also show a sudden increase in oxidation of Mo and Si layer between 60 and 100 hours of exposure. Interestingly, this matches the large change in SEY emission, increase in the surface roughness and decrease in reflectivity. Our hypothesis is that B forms volatile species with $-\mathrm{OH}$ or $\mathrm{H}$ and escapes the multilayer. It is likely that the oxidation is initiated at voids and pinholes in the $\mathrm{Ru}$ layer. When Ru oxidizes it expands, and perturbs the surface. This causes increased surface roughness and brings $\mathrm{Si}$ and Mo closer to the surface. This might explain the detection of Si and Mo at the surface with XPS.

Comparing the electron beam exposure results of Ru- and Si-capped multilayers, we find that the lifetime of Ru-capped multilayers is greater than of Si-capped. Both multilayers were exposed under the same conditions as described above. After 60 hour exposures we mapped the samples reflectivities at the peak wavelength using the reflectometer. The reflectivity as a function of wavelength was then measured in the center of the exposed area. The reflectance maps are show in Figure 8. The reflectivity of the exposed Si-capped multilayer dropped in the center of the exposed area by $17 \%$, while the reflectivity of exposed Ru-capped multilayer dropped in the center by only $2 \%$. There was no measurable change in the wavelength for either multilayer, confirming that the oxidation affected only the surface area. From the electron beam exposure tests we find that for the Ru-capped multilayer a reflectivity drop of $1.6 \%$ (corresponding to our criterion for failure) occurred after and exposure of $30 \pm 5$ hours at a current density of $500 \mu \mathrm{A} / \mathrm{cm}^{2}$. From previous experiments ${ }^{24}$ we determined the relationship between the current of the secondary electrons and the EUV power, to be 1 $\mu \mathrm{A}$ of electron beam corresponds to $3 \mathrm{~mW}$ of EUV exposure. Using this conversion factor, the dose for failure is therefore $D_{F}^{e}=500 \mu \mathrm{A} / \mathrm{cm}^{2} \times 3 \mathrm{~mW} / \mu \mathrm{A} \times 30 \pm 5$ hours $=1.62 \times 10^{5} \mathrm{~J} / \mathrm{cm}^{2}$ for the Ru-capped multilayers. 


\subsection{EUV exposures}

To verify the validity of the electron beam exposures we tested the oxidation resistance of Ru- and Si-capped multilayes also with EUV light in the presence of water vapor. Additionally, the plasma source operates as a pulsed source. In contrast, EUV light from a synchrotron source has a very narrow bandwidth and synchrotron is effectively a continuous source.

The 60-hour EUV exposures were performed with an average current density of $800 \mathrm{~mW} / \mathrm{cm}^{2}$ in a chamber with $2 \times 10^{-6}$ Torr of water vapor pressure as described in Section 2.7. Again, Ru- and Si-capped multilayers were exposed under identical conditions and the results are shown in Figure 9. The Ru-capped multilayer experienced a reflectivity drop of $1.5 \%$ while the Si-capped multilayer showed a reflectivity drop of $16.4 \%$. The surface roughness of Ru-capped multilayer increased from $0.19 \mathrm{~nm} \mathrm{rms}$ to $0.62 \mathrm{~nm}$ rms. This is a similar surface roughness increase observed on the electron beam exposed sample that experienced a similar reflectance drop. The surface roughness of as-deposited $\mathrm{Si}$ capped multilayers is typically $0.15-0.18 \mathrm{~nm}$. The Si-capped EUV exposed spot still has a smooth surface $(0.25 \mathrm{~nm} \mathrm{rms})$ but the reflectivity dropped by $17 \%$. The oxidation in Si-capped multilayers is not limited to the surface layer but had to change few more layers underneath in order to explain such a large reflectivity drop. These results imply that electrons and EUV exposures are similar. The exposure time at which the reflectivity dropped by $1.6 \%$ was $60 \pm 2$ hours. Thus, the dose for failure is $\mathrm{D}_{F}^{\mathrm{EUV}}=800 \mathrm{~mW} / \mathrm{cm}^{2} \times 60 \pm 2$ hours $=1.73 \times 10^{5} \mathrm{~J} / \mathrm{cm}^{2}$.

\subsection{Lifetime calculations}

The lifetime of the optical elements of an EUV projection imaging system depends on the power density on each of those elements during exposure. This, in turn, depends on the area of the optics, which will be specific to an optical design, on the reflectivity of the mirrors, and on the wafer throughput of the system. We chose for this study a sixmirror $0.25 \mathrm{NA}$ ring-field optic that has been published ${ }^{25}$, referred here as the Advanced Optical Package (AOP). The areas of the kidney-shaped clear apertures of each of the mirrors of this design are given in Table 1. To calculate the power densities at the mirrors, we assume that the mask pattern being printed is detailed, with a large variation in pattern shapes and sizes, so that the diffracted (ie all reflected) intensity from the mask uniformly illuminates the clear apertures of the mirrors. Furthermore, we assume that all the light diffracted from the mask remains within the acceptance numerical aperture (and acceptance field) of the optical system. We first compute the power required at the wafer to expose at a rate of a particular number of wafers per hour, and then work backwards through the system, to find the power required to be reflected from each mirror. The power at the wafer is simply given by the required dose to print ${ }^{26}$, $D_{\mathrm{w}}$, taken here to be $5 \mathrm{~mJ} / \mathrm{cm}^{2}$, multiplied by the printed area, $A_{\mathrm{w}}$. For a $300-\mathrm{mm}$ diameter wafer, this area is $707 \mathrm{~cm}^{2}$. Each wafer must be printed in a time $t_{\mathrm{w}}$ (we take $t_{\mathrm{w}}=36 \mathrm{~s}$ for 80 wafers/hour with a $20 \%$ overhead), which gives a required power incident on the wafer of $P_{\mathrm{w}}=D_{\mathrm{w}} A_{\mathrm{w}} / t_{\mathrm{w}}$. With the values given above, the required power is $98.2 \mathrm{~mW}$. With a mirror reflectance of $R$, the incident power on that mirror is $1 / R$ of the reflected power, and the power absorbed in the mirror is $(1-R) / R$ of the reflected power. Therefore, the power absorbed by the $n^{\text {th }}$ mirror in the sixmirror system is $P_{\mathrm{w}}(1-R) / R^{7-n}$. Since the mirror lifetime measurements are characterized by incident power, we compute the power incident on the $n^{\text {th }}$ mirror as $P_{n}=P_{\mathrm{w}} / R^{7-n}$. Note that we need not make any assumption in the way the wafer is exposed, nor do we need to know the area of the image field of the optic. All that is needed for the calculation is that the wafer must be patterned over a certain area, in a certain time, with a certain dose. All the photons that expose the wafer must have passed through the optical system within the same time required to expose the wafer.

Given an area $A_{n}$ of the clear aperture of mirror $n$ we now see that the power density incident on that mirror is given by

$$
J_{n}=P_{n} / A_{n}=P_{w} /\left(A_{n} R^{7-n}\right)=D_{w} A_{w} /\left(t_{w} A_{n} R^{7-n}\right),
$$

which can obviously be generalized to systems with other than six mirrors. The power densities of the mirrors of the AOP are given in Table 1, and it is seen for this particular design that mirror M1 receives the highest power density. Note that the equation is valid for the mask, for $n=0$ and $A_{n}$ set equal to the patterned area of the mask. We then compute mirror lifetimes from our experimentally determined dose for failure, $D_{F}$., which was found from the exposure time to fail (failure is taken to be a reduction in reflectivity of $1.6 \%$ ) multiplied by the equivalent EUV power density. 
As shown in Sections 3.1 and 3.2, we have $D_{F}^{e}=1.62 \times 10^{5} \mathrm{~J} / \mathrm{cm}^{2}$ from the electron-beam exposures and $D_{F}^{E U V}=1.73$ $\times 10^{5} \mathrm{~J} / \mathrm{cm}^{2}$ from the accelerated EUV exposures. That is, the lifetime of mirror $n$, in seconds, is $L_{n}=D_{F} /\left(0.8 J_{n}\right)$. Here we have accounted for the $20 \%$ overhead time of exposure. The lifetimes of the optics of the AOP design are given in Table 1, for the two estimates of $D_{F}$. For the highest dosed mirror, $\mathrm{M} 1$, the lifetime is based on electron beam extrapolation is 0.4 years and the lifetime based on EUV extrapolation is 0.3 years.

\section{SUMMARY}

A new capping layer design consisting of Ru-on-B4C-on-Si layer has been tested with accelerated electron beam and EUV light in water vapor environment. The results were compared with the results from standard Si-capped multilayer that were exposed under identical conditions. Lifetime calculations show that the $1.6 \%$ reflectance loss on Si-capped multilayers occurs within a week to a few months. Ru-capped multilayers have about 40x longer lifetime under identical conditions. Hence, the lifetime of Ru-capped multilayers is estimated to be 3 months to many years.

The results from electron beam exposures and EUV exposures are remarkably similar. This validates electron beam exposure experiments. Long electron beam exposures are more feasible because they do not require synchrotron source.

The Ru-capping layer is superior to Si-capping layer. However, the lifetime of Ru-capped multilayers on most mirrors still does not meet stringent commercial tool specifications. Improvements to existing $\mathrm{Ru}$ capping layer and new approaches to robust capping layer must be developed.

\section{ACKNOWLEDGMENTS}

We would like to thank Sherry Baker and Cindy Larson (LLNL) for AFM measurements, Charles Steinhaus (SNL) for helping out with the electron beam exposures, W. Miles Clift (SNL) for Auger depth profile data, Art Nelson (LLNL) for XPS analysis, and Donald Sweeney, John Taylor (LLNL) and Lennie Klebanoff (SNL) for useful discussions.

Work performed under the auspices of the U.S. Department of Energy by the Lawrence Livermore National Laboratory under Contract No. W-7405-ENG-48 and by Sandia National Laboratories under Contract DE-AC04-94AL85000. Funding was provided by the Extreme Ultraviolet Limited Liability Corporation under a Cooperative Research and Development Agreement.

\section{REFERENCES}

1. J. A. Folta, S. Bajt, T. W. Barbee Jr., R. F. Grabner, P. B. Mirkarimi, T. Nguyen, M. A. Schmidt, E. Spiller, C. C. Walton, M. Wedowski, and C. Montcalm, Advanced in multilayer reflective coatings for extreme-ultraviolet lithography, SPIE 3676, 702-709 (1999).

2. M. Putero-Vuaroqueaux and B. Vidal, Extreme-ultraviolet multilayer mirrors deposited using radio-frequencymagnetron sputtering: the influence of self-bias voltage on reflectivity and roughness, J. Phys.: Condens. Matter 13, 3969-3976 (2001).

3. E. Spiller, S. Baker, P. A. Mirkarimi, V. Sperry, E. Gullikson, and D. Stearns, High performance Mo/Si multilayer coatings for EUV lithography using ion beam deposition, submitted to Appl. Opt. (2003).

4. E. Louis, A. E. Yakshin, P. C. Görts, S. Oestreich, R. Stuik, E. L. G. Maas, M. J. H. Kessels, Bijkerk, M. Haidl, S. Müllender, M. Mertin, D. Schmitz, F. Scolze and G. Ulm, Progress in Mo/Si multilayer coating technology for EUVL optics, SPIE 3997, 406-411 (2000).

5. St. Braun, R. Dietsch, M. Haidl, Th. Holz, H. Mai, S. Müllender, R. Scholz, Mo/Si -multlayers for EUV applications prepared by pulsed laser deposition (PLD), Microelectr. Eng. 57-58, 9-15 (2001).

6. M. Shiraishi, N. Kandaka, K. Murakami, Mo/Si multilayers deposited by low-pressure rotary magnet cathode sputtering for extreme ultraviolet lithography, in this SPIE Proc.

7. S. Bajt, J. Alameda, T. Barbee Jr., W. M. Clift, J. A. Folta, B. Kaufmann, E. A. Spiller, Improved reflectance and stability of Mo-Si multilayers, Opt. Eng. 41, 1797-1804 (2002).

8. St. Braun, H. Mai, M. Moss, R. Scholz and A. Leson, Mo/Si multilayers with different barrier layers for applications as extreme ultraviolet mirrors, Jpn. J. Appl. Phys. 41, 4074-4081 (2002).

9. J. H. Underwood, E. M. Gullikson, and K. Nguyen, Tarnishing of Mo/Si multilayer $\mathrm{x}$-ray mirrors, Appl. Opt. 32, 6985-6990 (1993). 
10. D. P. Gaines, R. C. Spitzer, N. M. Ceglio, M. Krumrey, and G. Ulm, Radiation hardness of molybdenum silicon multilayers designed for use in a soft-x-ray projection lithography system, Appl. Opt. 32, 6991-6998 (1993).

11. L. E. Klebanoff, M. E. Malinowski, P. Grunow, W. M. Clift, C. Steinhaus, A. H. Leung, S. J. Haney, First environmental data from the EUV engineering test stand, SPIE 4343, 342-346 (2001).

12. M. Wedowski, S. Bajt, J. A. Folta, E. M. Gullikson, U. Kleineberg, L. E. Klebanoff, M. E. Malinowski, W. M. Clift, Lifetime studies of $\mathrm{Mo} / \mathrm{Si}$ and $\mathrm{Mo} / \mathrm{Be}$ multilayer coatings for extreme ultraviolet lithography, SPIE 3767, 217-224 (1999).

13. L. E. Klebanoff, W. M. Clift, M. E. Malinowski, C. Steinhaus, P. Grunow, and S. Bajt, Radiation-induced protective carbon coating for extreme ultraviolet optics, J. Vac. Sci. Technol. B 20, 696-703 (2002).

14. S. Oestreich, R. Klein, F. Scholze, J. Jonkers, E. Louis, A. Yakshin, P. Görts, G. Ulm, M. Haidl, and F. Bijkerk, Multilayer reflectance during exposure to EUV radiation, SPIE 4146, 64-71 (2000).

15. N. Koster, B. Mertens, R. Jansen, A. van de Runstraat, F. Stietz, M. Wedowski, H. Meiling, R. Klein, A. Gottwald, F. Scholze, M. Visser, R. Kurt, P. Zalm, E. Louis, A, Yakshin, Molecular contamination mitigation in EUVL by environmental control, Microelect. Eng. 61-62, 65-76 (2002).

16. M. E. Malinowski, C. A. Steinhaus, D. E. Meeker, W. M. Clift, L. E. Klebanoff, S. Bajt, Relation between electron- and photon-caused oxidation in EUVL optics, this SPIE Proc. (2003).

17. L. E. Klebanoff, P. A. Grunow, S. Graham, W. M. Clift, A. H. Leung, S. J. Haney, Environmental data from the Engineering Test Stand, SPIE 4688, 310-315 (2002).

18. E. Spiller, http://cletus.phys.columbia.edu/pxrms/, conference presentation at PXRMS'02, Chamonix Mont Blanc, France, 2002.

19. S. Graham, C. Steinhaus, M. Clift, L. Klebanoff, Radio-frequency discharge cleaning of silicon-capped Mo/Si multilayer extreme ultraviolet optics, J. Vac. Sci. Technol. B 20, 2393-2400 (2002).

20. S. Graham, C. E. Steinhaus, M. Clift, L. E. Klebanoff, S. Bajt, Atomic hydrogen cleaning of EUV multilayer optics, this SPIE Proc. (2003).

21. M. Singh, and J. J. M. Braat, Capping layers for extreme-ultraviolet multilayer interference coatings, Opt. Lett. 26, 259-261 (2001).

22. A.E. Yakshin, E. Louis, E.L.G. Maas, F. Bijkerk, R. Klein, F. Scholze, P. Zalm, F. Stietz, M. Wedowski, S. Muellender, B. Mertens, and $\mathrm{H}$. Meiling, Protection of $\mathrm{Mo} / \mathrm{Si}$ multilayers with a carbon capping layer, ASET/SEMATECH Workshop on Extreme UV Lithography, Matsue Vol. CD, pp. P6-6 (2001).

23. J. H. Underwood, and E. M. Gullikson, High-resolution, high-flux, user friendly VLS beamline at the ALS for the 50-1300 eV energy region, J. Electron Spectrosc. Relat. Phenom. 92, 265-272 (1998).

24. M. Malinowski, private conversation.

25. R. Hudyma,

26. D. O'Connell 


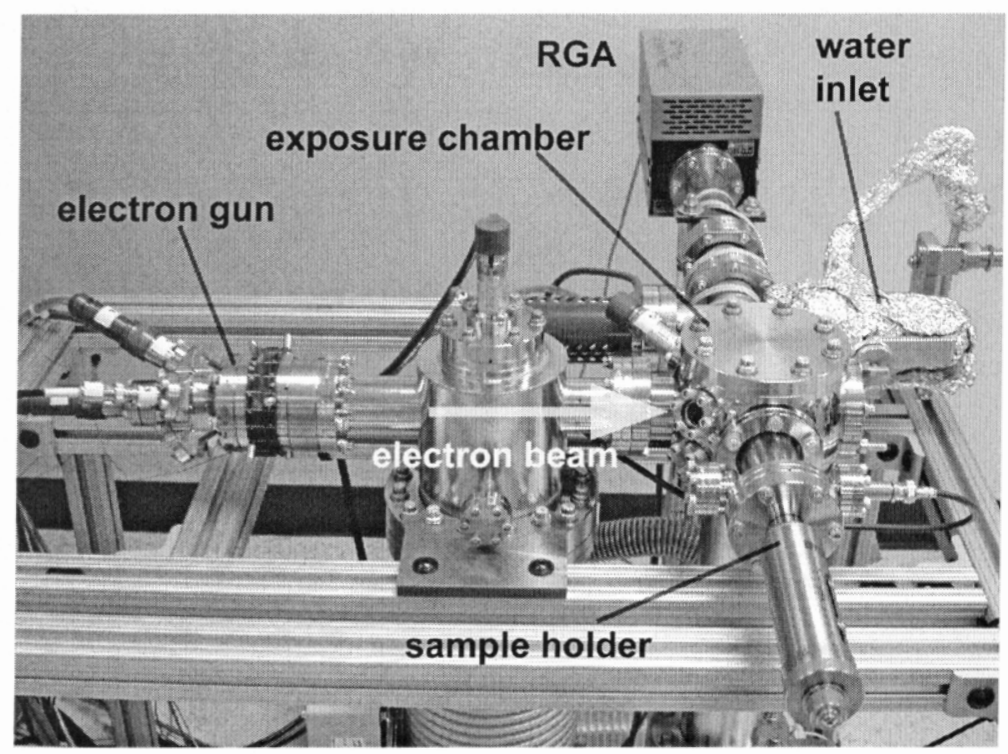

Figure 1: A photo of the electron beam chamber at Sandia National Laboratory, which was used for electron beam exposures. 


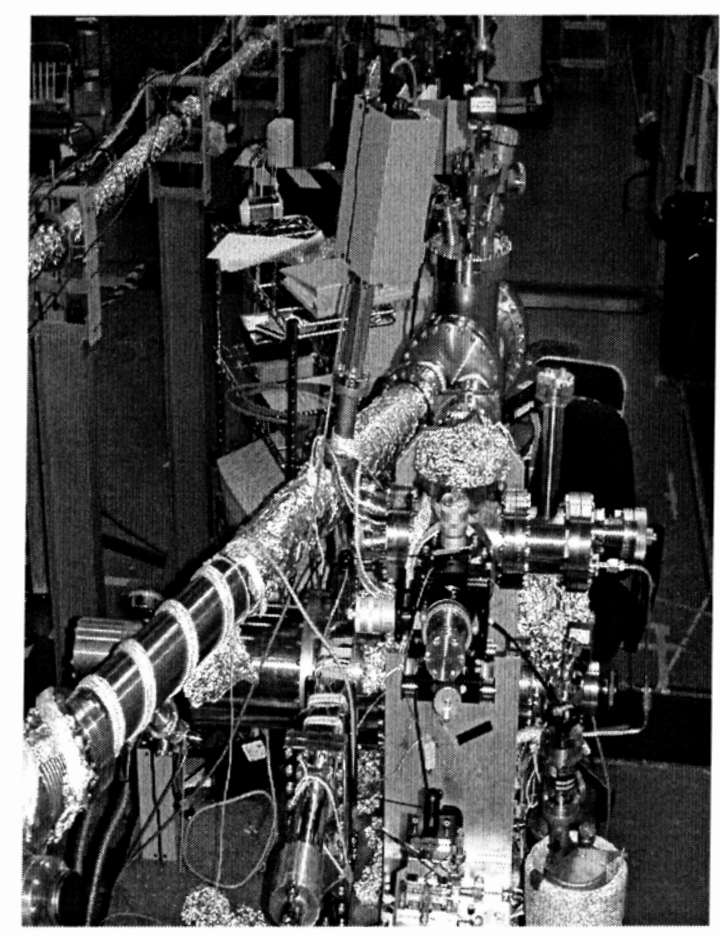

Figure 2: A photo of the NIST environmental chamber used for EUV light exposures.

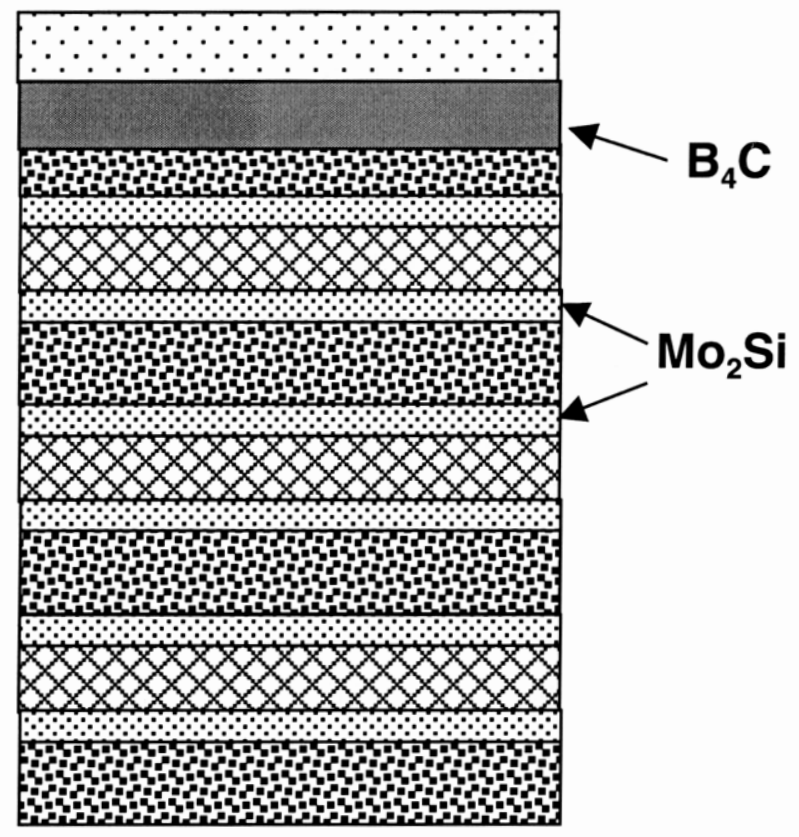

Figure 3: Schematic view of capping layer design and the multilayer in this study. 


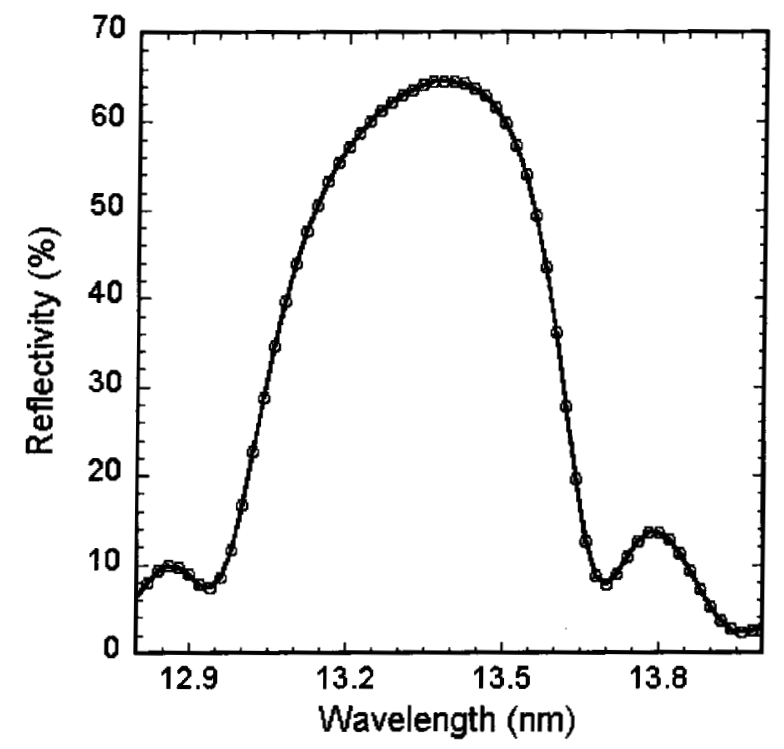

Figure 4: Reflectivity as a function of wavelength of a Ru-capped multilayer.

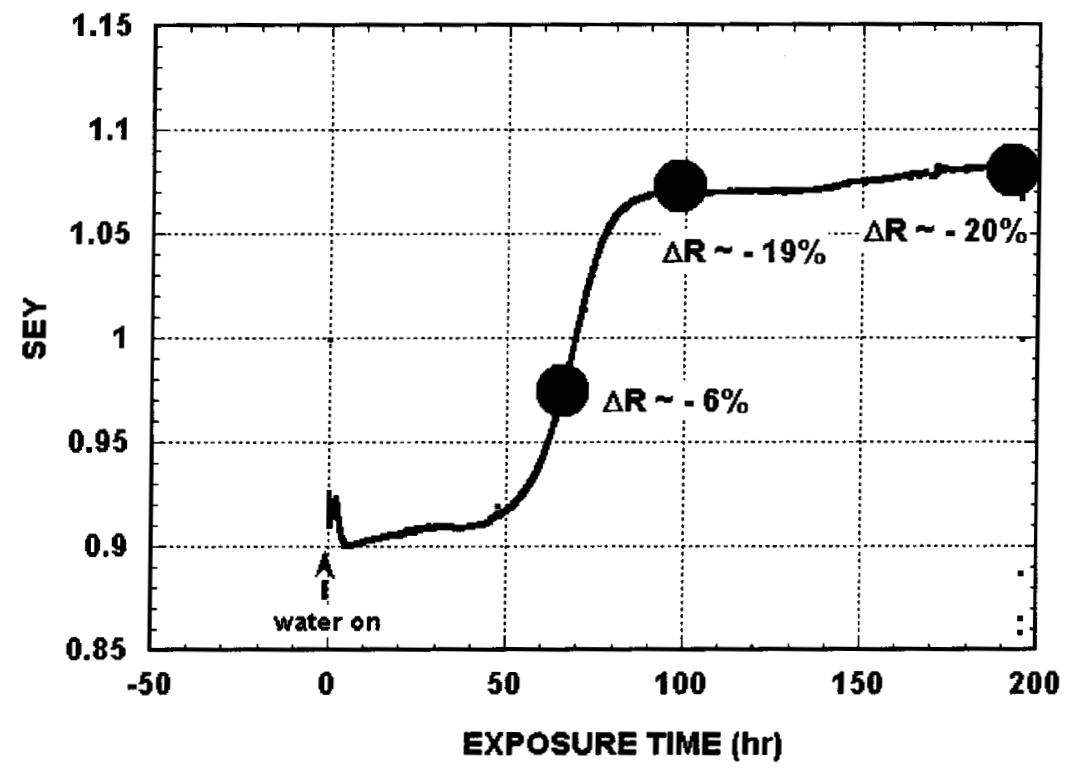

Figure 5: Secondary electron yield (SEY) emission as a function of exposure time shows a sudden increase after $\sim 50$ hours of electron beam exposure in water vapor environment. Shown here is also reflectance drop (absolute values) as a function of the exposure time. 

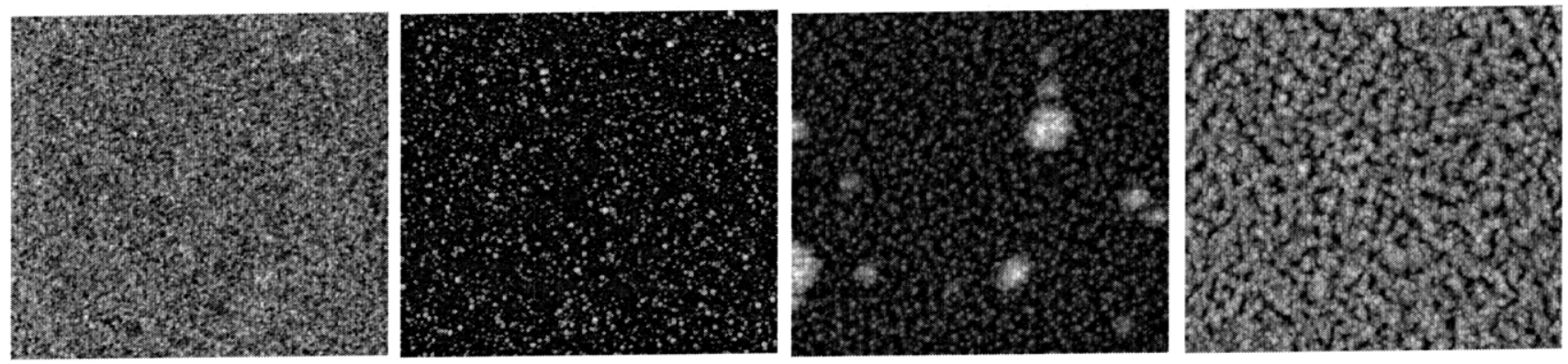

Figure 6: Two dimensional AFM scans $\left(2 \times 2 \_\mathrm{m}\right)$ on a Ru-capped multilayer on an unexposed area (a), on the area exposed to 60 hours (b), 100 hours (c) and $\sim 200$ hours (d). The measured RMS surface roughness: $0.19 \mathrm{~nm}$ (a), $1.19 \mathrm{~nm}$ (b), $2.87 \mathrm{~nm}$ (c) and $1.65 \mathrm{~nm}$ (d).

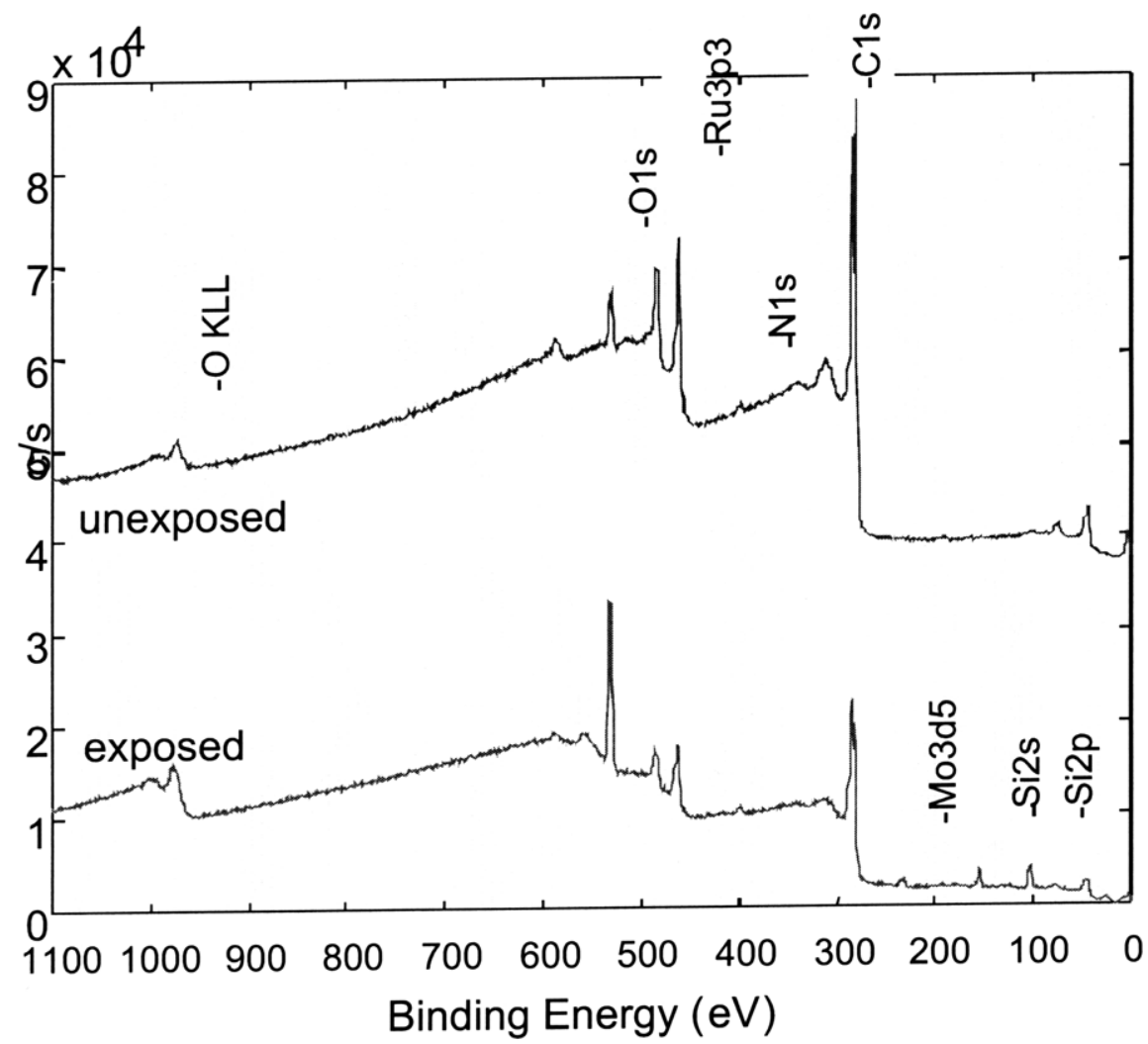

Figure 7: XPS spectra of unexposed Ru-capped multilayer and of Ru-capped multilayer that was exposed to the electron beam in the presence of water vapor for 100 hours. 

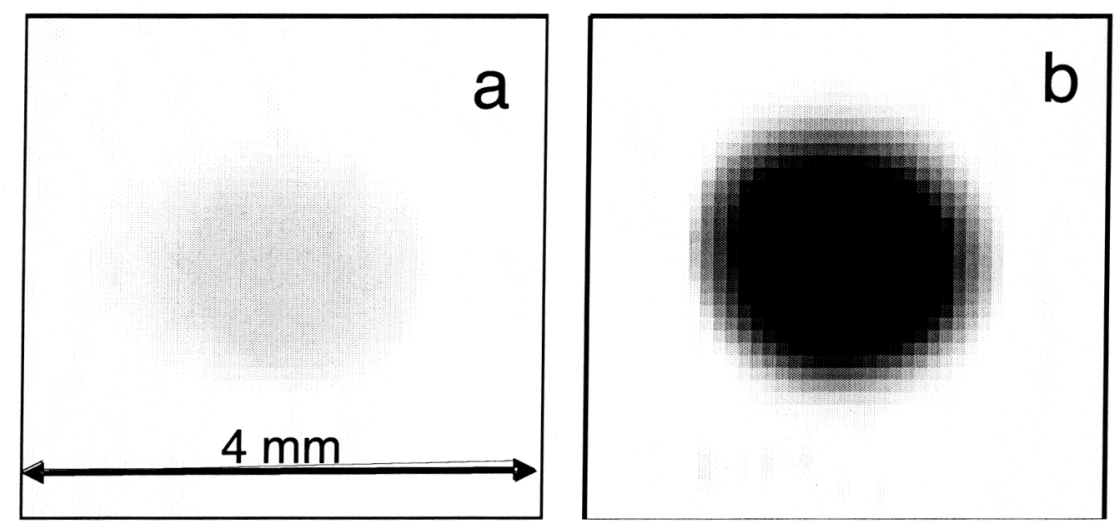

Figure 8: Reflectance maps on Ru-capped multilayer (a) and Si-capped multilayer (b) after $\sim 60$ hours of electron beam exposure in water vapor environment. The greyscale is the same for both maps and ranges on a linear scale from $-17 \%$ (black) to $0 \%$ (white).

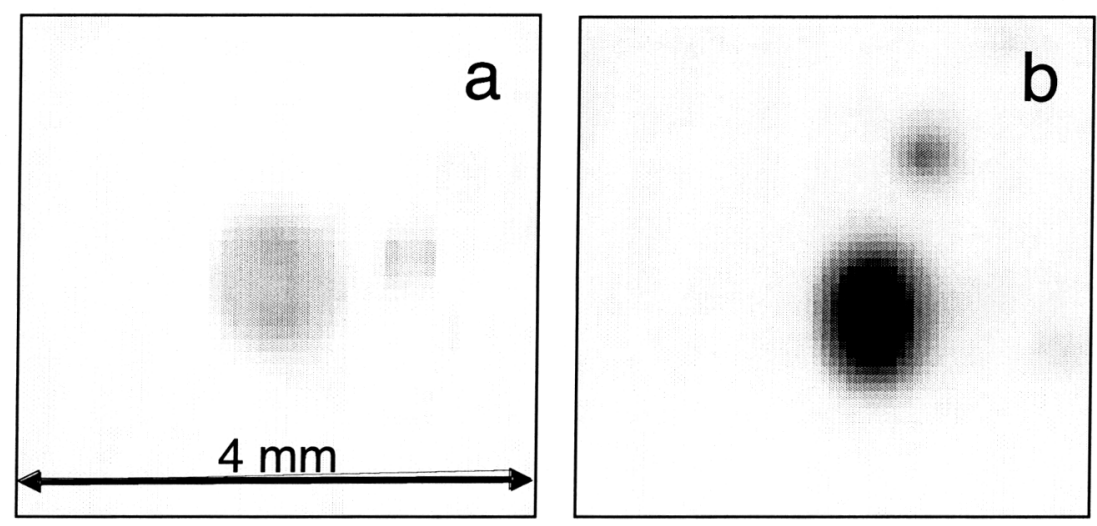

Figure 9: Reflectance maps on Ru-capped multilayer (a) and Si-capped multilayer (b) after $\sim 60$ hours of EUV beam exposure in water vapor environment. The greyscale is the same for both maps and ranges on a linear scale from $-16.5 \%$ (black) to $0 \%$ (white).

Table 1: Lifetime calculations based on electron beam extrapolations $\left(\mathrm{L}_{\mathrm{e}}\right)$ and EUV beam extrapolations ( $\left.\mathrm{L}_{\mathrm{EUV}}\right)$. The lifetimes based on electron beam extrapolations are the lower limit values.

\begin{tabular}{|c|c|c|c|c|}
\hline & $\begin{array}{c}\text { Area } \\
\left(\mathrm{cm}^{2}\right)\end{array}$ & $\begin{array}{c}\boldsymbol{P} \\
\left(\mathrm{mW} / \mathrm{cm}^{2}\right)\end{array}$ & $\begin{array}{c}\mathbf{L}_{\mathrm{e}} \\
\text { (years) }\end{array}$ & $\begin{array}{c}\text { Leuv } \\
\text { (years) }\end{array}$ \\
\hline Mask & 161 & 43.3 & 0.15 & 0.12 \\
\hline M1 & 127 & 17.5 & 0.4 & 0.3 \\
\hline M2 & 162 & 8.7 & 0.7 & 0.6 \\
\hline M3 & 78 & 11.1 & 0.6 & 0.5 \\
\hline M4 & 495 & 1.0 & 6.4 & 5.6 \\
\hline M5 & 39 & 7.5 & 0.9 & 0.7 \\
\hline M6 & 536 & 0.3 & 21.4 & 18.5
\end{tabular}

